\title{
Integrated Analysis of The Influence of Culture, Tradition, and Ethnicity On The Consumption Pattern Of Consumers: Evidence From Agrarian Settlement In Nigeria.
}

\author{
Elisa Ehinmilorin \\ Westcliff University Irvine, Department of Business Administration, \\ 17877 Von Karman Avenue \#400, Irvine, California 92614. \\ Email: e.ehinmilorin.300@westcliff.edu
}

\begin{abstract}
The study examined the influence of culture and ethnicity on the consumption pattern of consumers in an agrarian settlement in Nigeria. Simple random sampling technique was adopted in selecting a total number of 70 respondents who provided requisite data for the study. The study employed the descriptive and inferential statistics (Probit regression) in analyzing data collected from the respondents. The result of the descriptive statistics revealed that more than $50 \%$ of the total respondents supported the view that culture and ethnicity have great influence on the consumption pattern of consumers in Nigeria. Also, the Probit regression result revealed that out of the 5 explanatory variables, religion, education and customs and tradition have significant influence on consumption pattern of consumers in the country. This was given the fact that the coefficient of religion was significant at $1 \%$, that of education was significant at $5 \%$ while that of customs and tradition was significant at $10 \%$ level of significance. Based on the findings of the study, it was concluded that Nigeria's cultural and ethnic diversity is responsible for varying levels of consumption pattern amongst different consumers. Therefore, the study recommended for better cultural tolerance and awareness of all and sundry to ensure a more fruitful cultural and ethnic cohesion and also to foster unity in diversity.
\end{abstract}

Keywords: Consumption, ethnicity, tradition, culture, pattern

DOI: $10.7176 / \mathrm{JCSD} / 66-08$

Publication date:August $31^{\text {st }} 2021$

\section{Introduction}

The issue of culture and ethnicity in the dealings of consumers has attracted astute attention in recent times. The behavior of humans irrespective of where they come from or where they reside cannot be said to be certain. According to Umoren (1996) humans strive to associate with one another with a view to ensuring that everyone live in peace and harmony. This implies that starting from birth, humans need to learn how to associate with each other and how to be acceptable by fellow members of the society. As pointed out Ijewere et al. (2012), humans are social beings and therefore, cannot live in isolation. This shows that all humans regardless of culture and ethnicity must always learn to live with one another in the society. Nevertheless, society has a strong effect and plays a critical role in shaping human values, belief system and overall ideology (Durmaz, 2014). The way people behave overtime, their actions, norms and attitudes are often determined by the societal influences gotten from the society. As a matter of fact, most of these values and belief systems are passed from one generation to another and are not values created by a single individual. Oftentimes, these norms, values and belief systems are inculcated through daily learning in the society and acquired experiences which are the major behavioural regulators (Kotler, 2002). In his work, De-Silva et al. (2010) noted that other smaller units of the society such as the peer groups, family, church, work, school amongst others are the major linkage through which these values and belief systems are transmitted.

Essentially, if cultural values, norms and belief system have a strong impact on human behavior, then it is likely to impact the consumption pattern of consumers. As pointed out by Speiers et al. (2014), most scholars in the culture literature have discovered a growing relationship between culture and consumption pattern. Accordingly, given the issues of globalization, civilization, industrialization and other factors of cross-cultural underpinnings, it is pertinent to consider how culture and ethnicity affects the consumption patterns of individuals. Inasmuch as the consumption pattern of a Chinese man will differ significantly from that of an American or a Japanese so also will the consumption pattern of a Yoruba man differ significantly from that of an Hausa or an Igbo man as the case may be. In the work of Antwi-Boateng et al. (2013), it is believed that if a lot of factors influence consumption patterns. These factors cut across attitudes of persons, emotions, values, individual personality, economic factors and cultural factors. Each of all these factors influences the pattern of consumption as well as decisions consumers make in their consumption dealings. Other factors include; experiences gathered overtime, availability of resources, peer groups, religion, knowledge, feelings, lifestyle amongst others. Sethi et al. (2014) stated that while people in one society display attitudes of thriftiness others may not and this depends on their 
respective culture.

In the Nigerian society, ethnicity and cultural values are fundamental factors determining consumption decisions of virtually all consumers. Nigeria is a multicultural society having more than 250 ethnic groups with different languages and cultural values. Some of these ethnic groups are adamant and usually resist change. Therefore, any attempt at changing certain consumption patterns might not be successful. Other times, individuals see their culture as divine and something given to them by God and passed down to them from their forefathers. In this sense, it becomes difficult to change these cultural values. Also, as pointed out by Blythe (2008), religion is also a fundamental determinant of consumption in the Nigerian society. For instance, Muslims do not eat pork because it is believed that pig is an unclean animal and their religion forbids the consumption of unclean things. In that sense there is no amount of advertisement or marketing strategy that will ensure a change of attitude. Therefore, the establishment of pork business in a Muslim society will be regarded as an exercise in futility.

Accordingly, Antwi-Boateng et al. (2013) noted that in line with cultural and ethnic values, issues of age affect consumption patterns and decisions of consumers as people tend to change their consumption patterns as they grow older due to health-related reasons. Therefore, as people grow older it is expected that their consumption of some goods reduces while that of others increases as the case may be. This also holds it basis on cultural values despite having health relations. The reason is that, some cultures will prefer the consumption of a certain kind of good at a younger age and the consumption of another at an older age.

Overall, since the turn of the $21^{\text {st }}$ century, culture, ethnicity and in some cases social class have been identified as major determinants of consumers consumption pattern in Nigeria. As pointed out by Kotler (2001), one of the most important influencers of consumers' buying decisions and behavior is culture. In supporting this view, Ijewere et al. (2012) noted that amongst all factors influencing the decisions of consumers regarding what to and what not to buy, culture has the broadest and deepest influence. Therefore, it is against this backdrop that this study seeks to evaluate the influence of culture and ethnicity on the consumption pattern of consumers in Nigeria.

\subsection{Literature Review \\ 2.1 Culture and Ethnicity}

The concept of culture and ethnicity have been variously defined and conceptualized. Generally, culture can be looked at as the way of living in total that is characteristic of a particular region, society or nation. Rani (2014) noted that culture is that which forms the basis for character creation and development. Also, Kotler et al (2010) stated that one of the basic determinants of a person's behavioural tendencies which cut across wants and others is culture. Therefore, the concept of culture is generic and involves belief system, values, norms, behavior, attitude amongst others. On the other hand, Ijewere et al. (2012) pointed out that ethnicity is the categorization of persons based on some similar factors which they share in common. Most of these factors include; identity, values, culture, language, tradition, religion, ancestry amongst others. Therefore, it is not surprising that ethnicity goes in line with culture. Where ethnicity exists, there will be differences in culture. The implication of this is that those having similar culture and identity will be grouped together and referred to as a particular ethnic group. Nevertheless, culture and ethnicity are fundamental at influencing consumption patterns both within a country and between countries. Particularly, for a nation like Nigeria with great cultural diversity, the issue of varying consumption patterns given varying ethnic categorization and cultural diversity will suffice.

\subsection{Consumption Pattern}

Kotler et al. (2009) stated that consumption pattern is the approach and strategy through which consumers make decisions regarding what to and what not to buy. Generally, the goal of consumers is the maximization of their satisfaction subject to their income constraint. Therefore, in order to maximize their satisfaction, consumers will buy and consume products consistent with their desires and values. Furthermore, in his work Antwi-Boateng et al. (2013) stated that consumption pattern comprise of the conglomeration of qualities, acts and quantities forming a basis for the characterization of a consumer's need for survival enjoyment and overall comfort. Consumption patterns are usually being observed by consumers' behavior about what they buy and also about critical decisions consumers make while carrying out their consumption activities. As pointed out by De-Silva et al (2010), the consumers are the last category of participants in the production chain. This implies that production is not complete until it gets to the final consumers. Therefore, the importance of consumers in the economy cannot be overemphasized and the need to evaluate consumers' consumption patterns. Accordingly, consumers in different regions and parts of the country have different tastes, preferences and expectations. Taking all those into consideration, it is pertinent to note that what constitutes the consumption pattern of what consumer in one region may not constitute the consumption pattern of another pattern in another region even within the same country. Solomon (2011), stated that given the varying nature of consumption patterns existing 
even within the same nation it is important for businesses involved in satisfying consumers to fully understand each of these patterns. Therefore, work has to be done on understanding the products which appeals to a particular culture and the products which do not as doing this will ensure that the needs of different consumers having different consumption patterns are equally met.

\subsection{Theoretical Review}

Anyanwu (1993) stated that there exists more ethnic groups and cultures than there exist nations in the world. More importantly, the varying levels of culture existing in the world have specific principles which govern them and are not based by value judgments or personal opinions of individuals. Nevertheless, several theories have been formulated in explaining the linkage between cultural and ethnic diversities and its effect on consumption pattern. Amongst all of these theories and models developed at explaining issues of cultural differences, Hofstede model has been regarding as the most comprehensive. This is because it not only explains cultural differences within countries but also between countries. Hofstede model was based on five dimensions which explain issues of varying cultures. These dimensions include; Masculinity, Individuality, Power Distance, Uncertainty Avoidance and Long-term Orientation. These dimensions reflect the complexities involved in explaining the nature of consumption patterns of consumers.

Also, with a view to explaining the complex nature of consumption pattern of consumers, Howard and Smith developed a theory in 1969 for understanding the behavioural consumption patterns of consumers given several influencing factors. They argue that when consumers form a habit about a particular product, they tend to purchase that product regardless of the price or any other reason. Furthermore, issues of price, product, place and promotion which comprise the 4 Ps of marketing are major influencer of consumption pattern of consumers.

Essentially, Kotler et al. (2009) noted that there has been overall success in international market dealings as a result of growing ability of participants at understanding to a large extent cultural and ethnic differences. When cultural and economic boundaries are removed, it will not only improve competition in the worldwide marketplace but also improve the understanding of different cultures, customs, traditional belief, habits etc.

\subsection{Empirical Review}

The literature is replete with several studies which have provided empirical debates concerning the linkage between culture and ethnicity and consumption patterns of consumers. A study by De Silva, Atapattu and Sandika (2010) in Sri Lanka examined the socio-cultural factors related with the purchasing of meat and consumption pattern. The findings of the study revealed that while most of the persons preferred a particular type of meat others preferred others. Also, the findings of the study revealed that a significant and high level of correlation exist between the type of meat consumed and factors such as age, religion, family size, culture and sex but not with the type of education, or occupation. Furthermore, the findings of the study revealed that a negative correlation exists between meat and age while the major factors influencing consumption behavior of meat by consumers were religious beliefs, financial resources and children's preferences.

Similarly, a study was carried out by Nkang and Effiong (2014) on the influence of consumption pattern of consumers on consumption of pork and poultry meat in Cross River State, Nigeria. They employed the techniques of both descriptive and inferential statistics through the use of Probit regression analysis. The sampling method employed was multi-stage in which 50 poultry and pork meat consumers were selected and included in the study. The result of the study was startling as educational level was found to significantly impact consumption pattern of consumer and was significant at 5\% level. However, several factors such as occupational, age, tastes and marital status were positive but statistically insignificant implying that they have no influence on the consumption of poultry and pork meat of consumers. Other significant factors were gender and price of the commodity which had negative influence on their consumption of poultry and pork and statistically significant at the $10 \%$ level.

In Ghana, Antwi-Boateng and Asaumah (2013), examined the factors influencing the consumption pattern of poultry meat amongst consumers in Ghana. The study revealed that cultural values made some consumers consider pork as distasteful. As such majority of consumers preferred poultry meat to the consumption of pork. The study further revealed that other factors besides culture which influences the buying decisions of consumers include; age, price of the commodity and taste of the consumer. These factors were found to be statistically significant in the study.

Overall, the reviewed literatures have revealed that culture and ethnicity influence the pattern of consumption especially by consumers in Nigeria. However, there is observed gap in the study because most of the studies 
focused more on other factors such as age, taste, family size and income without putting much attention on culture. Furthermore, none of the studies examined the rate of impact of each of the cultural factors on consumption patterns in Nigeria. Also, the literature on culture, ethnicity and consumption pattern of consumers in Nigeria is insufficient as most of the reviewed studies were carried out in neigbouring countries. All these constitutes the observed gap in literature and therefore, this study seeks to fill such gap by examining empirically, the influence of culture and ethnicity on consumption pattern of consumers in Nigeria with a view to providing requisite findings and solutions which will assists not just businesses in knowing how to serve persons with different cultural values but also the consumers themselves for them to fully understand the cultural characteristics of others such that everyone can live in peace and harmony respecting each other's cultural peculiarities.

\subsection{Methodology}

3.1 Research Design

Sethi (2014) pointed out that a research design is a plan or blueprint of how the researcher intends on conducting the research. It considers the constraints such as access to data, location, time and money that would be inevitably encountered, as well as ethical issues relating to the research (Bearden et al. 2004). This study was carried out by using an Ex-post facto research design. According to Rani (2014), Ex-post facto research design as a scientific method focuses on describing or defining a subject's behavior through the analytical use of frequencies, tables, percentages and inferential statistics.

\subsection{Research Approach}

This study adopted the qualitative and quantitative research approach in investigating the influence of culture and ethnicity on consumption pattern of consumers in Nigeria. Qualitative research is a form of social action that stresses on the way of people interpret, and make sense of their experiences to understand the social reality of individuals. On the other hand, quantitative research involves the use of inferential statistics in understanding the impact of one variable on another.

\subsection{Target Population}

According to Blythe (2008), population is a group of people or objects in a particular social or biological setting from which data is gathered in research. Similarly, HemaPatil et al., (2012), describe population as consisting of all the elements which forms the unit of analysis. The target population for this study includes consumers of all products regardless of age, marital status, gender, religion amongst others. This is done so as to be able to capture vividly the impact of culture and ethnicity on the consumption patterns of consumers.

\subsection{Sampling Technique}

Simple random sampling procedure was employed in the study through the use of a well-developed questionnaire. The questionnaire was developed appropriately in order to ensure that the views and opinions of consumers regarding culture and ethnicity and its effect on their consumption pattern were adequately captured. A total number of 83 questionnaires were administered and 70 were fully attended to and recovered.

\subsection{Method of Data Analysis}

The study employed descriptive statistics through the use of percentages, graphs, tables and frequencies and as well as the Probit regression model to evaluate the influence of cultural and ethnicity factors on the consumption patterns of consumers.

\subsection{Model Specification}

The study employed both descriptive and inferential statistics in examining the influence of culture and ethnicity on the consumption pattern of consumers. Therefore, to determine the influence which culture and ethnicity exert on consumption pattern, the following model will be employed;

$\mathrm{Y}=\alpha_{0}+\alpha_{1} \mathrm{X}_{1}+\alpha_{2} \mathrm{X}_{2}+\alpha_{3} \mathrm{X}_{3}+\alpha_{4} \mathrm{X}_{4}+\alpha_{5} \mathrm{X}_{5}+\mathrm{U}_{\mathrm{t}}$

Where; $\mathrm{Y}=$ The dichotomous endogenous variable which was proxied as; $\mathrm{Y}=1$, if respondents agree that culture and ethnicity influence their consumption pattern, $\mathrm{Y}=0$, if respondents do not agree that culture and ethnicity influence their consumption pattern.

$\alpha_{0}=$ intercept

$\alpha_{1}-\alpha_{5}=$ Partial regression coefficients explaining the impact of the control variables on the dependent variable.

$\mathrm{U}_{\mathrm{t}}=$ Stochastic Disturbance Term

Given the above the implicit representation of the model is given as;

$\mathrm{Y}=\mathrm{f}\left(\mathrm{X}_{1}, \mathrm{X}_{2}, \mathrm{X}_{3}, \mathrm{X}_{4}, \mathrm{X}_{5}, \mathrm{U}_{\mathrm{t}}\right)$

$\mathrm{Y}=$ Consumption pattern of consumers 
$\mathrm{X}_{1}$ to $\mathrm{X}_{5}=$ The explanatory variables which show how cultural and ethnic factors influence consumption pattern. They are given below as;

$\mathrm{X}_{1}=$ Values (If Yes $=1$, if No $=0$ )

$\mathrm{X}_{2}=$ Religion (If Yes $=1$, if $\mathrm{No}=0$ )

$\mathrm{X}_{3}=$ Education (If Yes $=1$, if $\mathrm{No}=0$ )

$\mathrm{X}_{4}=$ Customs and Tradition (If Yes $=1$, if $\mathrm{No}=0$ )

$\mathrm{X}_{5}=$ Social Organization (If Yes $=1$, if $\mathrm{No}=0$ )

\subsection{Results}

A total number of 83 questionnaires were administered but 70 , representing $84.3 \%$ of the total questionnaires were returned and subsequently analyzed.

Table 1: Questionnaire Distribution

\begin{tabular}{|l|l|l|}
\hline Particulars & Frequency & Percent (\%) \\
\hline Returned & 70 & 84.3 \\
\hline Not returned & 13 & 15.7 \\
\hline Total & $\mathbf{8 3}$ & $\mathbf{1 0 0}$ \\
\hline
\end{tabular}

Source: Field Survey, 2021

Table 2: Demographic Characteristics of Respondents

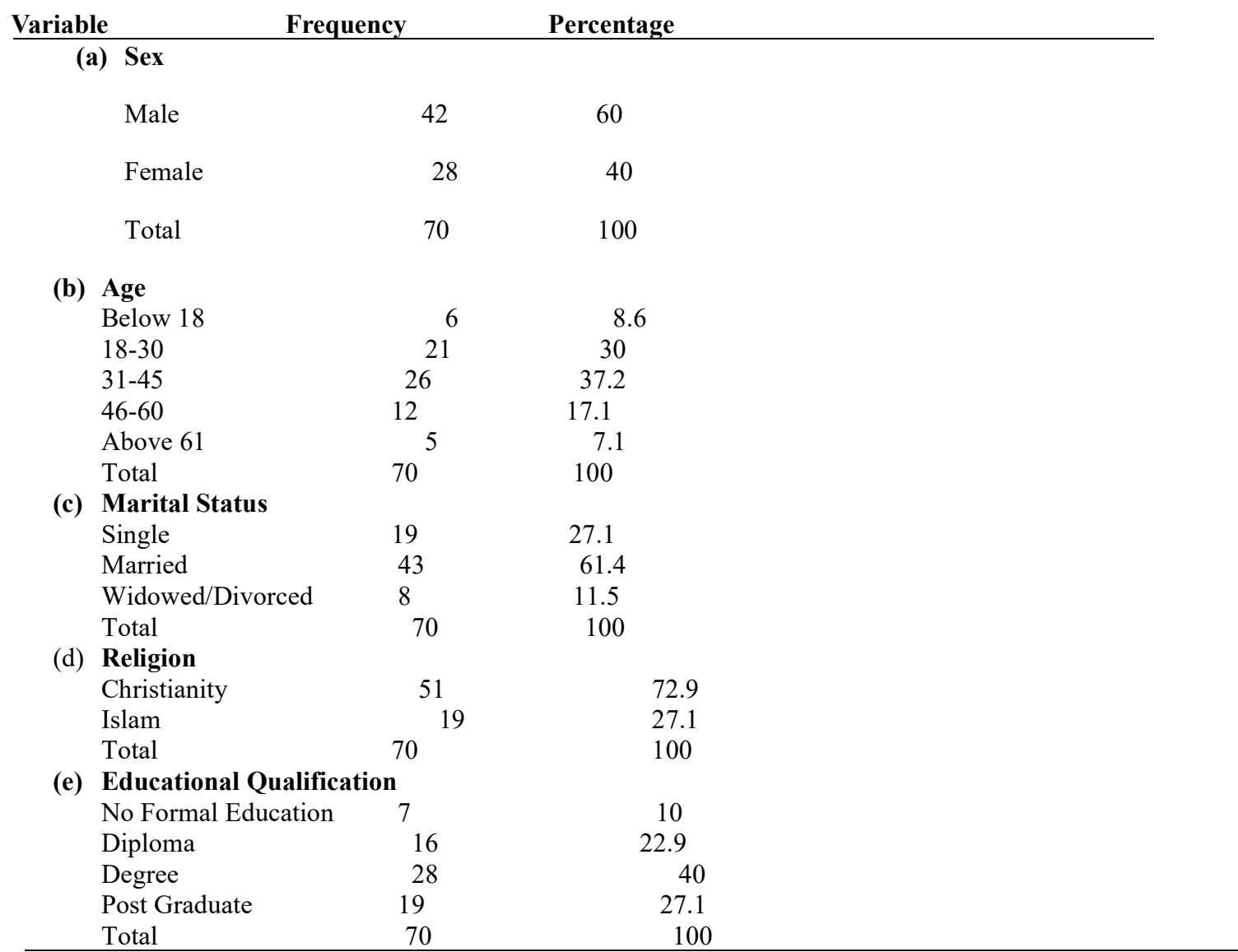

Source: Researcher's Computation

\subsection{Culture, Ethnicity and Consumption Pattern}

In order to tackle the major objective of this study which is to investigate the influence of culture and ethnicity on consumption pattern of consumers in an agrarian society in Nigeria, the study employed the Likert scale statistical technique in which the respondents were asked to indicate the extent to which they support the idea that culture and ethnicity influences the pattern of consumption of consumers in Nigeria. This Likert scale 
technique was structured such that there were one to five options to which respondents were to indicate their choice which include, Not at all, Little extent, Moderate extent, Great extent and Very great extent. This structure implies that respondents whose idea is that culture and ethnicity has no significant influence on consumption patterns of consumers in Nigeria selected the Not at all option or little extent option depending on the view of each respondent. Similarly, respondents whose idea is that culture and ethnicity has significantly influence consumption patterns of consumers in Nigeria selected the great extent and very great extent depending on the view of each respondent. The responses of all respondents are illustrated in the chart below;

\section{Figure 1: Culture, Ethnicity and Consumption Pattern}

\section{Extent to which Culture and Ethnicity Influence Consumption Pattern of Consumers in Nigeria}

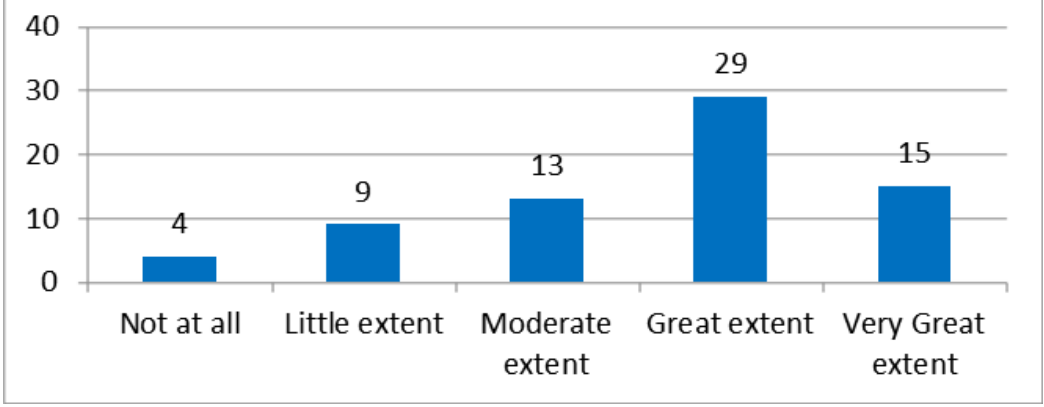

\section{Source; Researcher's Computations}

From the chart above, it can be observed that of the total number of 70 respondents who gave their view as regards the influence of culture and ethnicity on consumption pattern of consumers in Nigeria, 4 chose Not at all which comprise of just approximately $5.7 \%$ of the total respondents. Therefore, it is the view of the 4 respondents that culture and ethnicity does not influence consumption pattern of consumers in Nigeria. In the same vein, 9 of the 70 respondents who comprise approximately $12.9 \%$ of the respondents chose little extent. This implies that 9 persons are of the view that culture and ethnicity has little impact on consumption pattern of consumers in Nigeria. Furthermore, the chart shows that 13 of the 70 respondents which comprise approximately $18.6 \%$ of the total respondents are of the view that culture and ethnicity has moderate influence on consumption pattern of consumers in Nigeria. Also, the chart revealed that 29 persons who comprise approximately $41.4 \%$ of the total respondents selected the great extent option. This implies that $41.4 \%$ of the respondents are of the view that culture and ethnicity exert great influence on consumption pattern of consumers in Nigeria. Finally, 15 persons who comprise approximately $21.4 \%$ of the total respondents selected the very great extent option. This indicates that $21.4 \%$ of the total respondents are of the view that culture and ethnicity exert very great influence on consumption pattern of consumers in Nigeria.

Table 3: Result of the Probit Regression Model

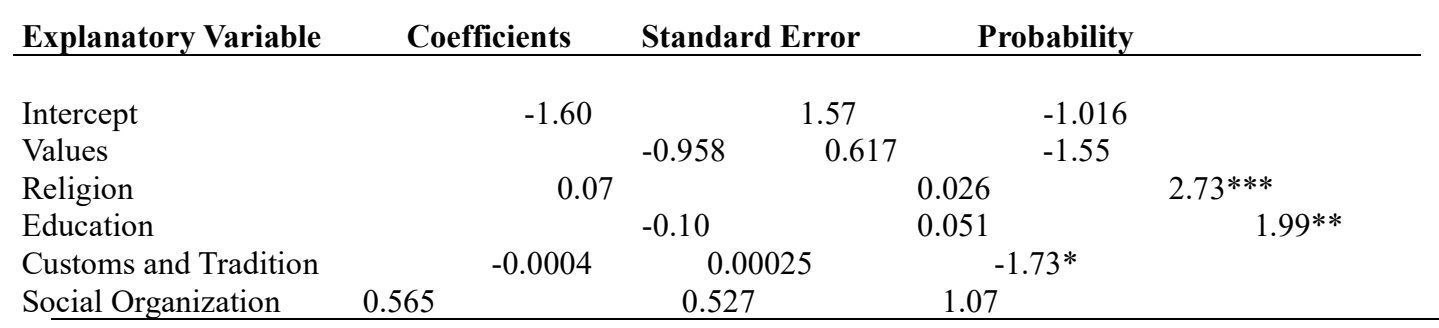

Source: Researcher's Computation Using SPSS (2021).

Standard error of regression $=0.430819 ;$ Log Likelihood $=-45.70794 ; R^{2}=0.6723 ;$ Adj. $R^{2}=$ $0.552 ; * * *$ shows that $\mathrm{p}$-value significant at $1 \% ; * *$ shows that $\mathrm{p}$-value is significant at $\mathbf{5 \%}$; * shows that p-value is significant at $10 \%$.

\subsection{Discussion}

The result of the Probit regression model in table 3 shows that the model has a good explanatory power given by a coefficient of multiple determination of approximately $67 \%$. This indicates that the explanatory variables explained $67 \%$ of the total variation in consumption pattern in Nigeria. The remaining 33 can is attributed to the 
stochastic disturbance term. Therefore, there is joint significance of the explanatory variables employed in the study. From the result, the intercept, coefficients of values, education and customs and tradition had negative signs. However, religion and social organization have positive signs implying a positive relationship with consumption pattern. Also, looking at the statistical significance of the results, the coefficient of values and social organization were found to be insignificant at both 1,5 and $10 \%$ levels of significance. This implies that according to the respondents' values and social organization are not important variable determining the pattern of consumption of consumers in Nigeria. However, the coefficient of religion was significant at the $1 \%$ level of significance. This implies that an increase in religious diversity by one unit will lead to an increase in the probability for not defaulting in a particular choice of consumption by the consumer. This shows that a person's religious belief is a major influencer of his consumption pattern. This finding is not surprising as it supports the view of other researchers reviewed in the empirical framework that religion is an important determining factor of consumption pattern of consumers in Nigeria. Also, the coefficient of education was found to be significant at the 5\% level of significance. This implies that an increase in education of the consumers by one unit will lead to an increase in the probability for not defaulting in a particular choice of consumption by the consumer. This shows that the level of education exposure one had is a major determinant of such a person's consumption pattern. Higher level of education exposure is consistent with higher effect on the consumption pattern of such a consumer. Finally, the coefficient of customs and traditions was found to be statistically significant at the $10 \%$ level of significance. This implies that an increase in the effect of customs and traditions by one unit will lead to an increase in the probability for not defaulting in a particular choice of consumption by the consumer. This shows that a person's tradition and customs is positively related to his consumption pattern. The higher the effect which customs and tradition exert on an individual, the higher will be the accompanied effect on his consumption pattern.

\subsection{Conclusion}

The study empirically examined the influence of culture and ethnicity on consumption pattern of consumers in Nigeria. The issue of culture and ethnicity and its relation to consumption dates back to ages and has earned the interest of many scholars. However, the study also revealed that apart from varying cultures which exist between countries, a large number of cultural differences also exists within a particular nation. The study employed descriptive and inferential statistics as method of analyzing data gotten from the respondents. The descriptive analysis revealed that more than half of the total respondents supported the view that culture and ethnicity exert great influence on consumption pattern of consumers in Nigeria. Similarly, the Probit regression analysis revealed that religion, education and customs and traditions are significant at explaining the rate of variation in consumption in the country. Therefore, it is concluded that cultural and ethnic factors are crucial at explaining patterns of consumption and therefore should not be taken with hands of levity.

\section{References}

Antwi-Boateng, C. Owusu-Prempeh, V. \& Asuamah, S.Y. 2013. "Assessment of Factors Influencing the Consumption of Pork and Poultry in Ghana: A Comparative Study" International Journal of Innovative Research in Management 2(4) Pp. 1-12.

Anyanwu, A. 1993. "Dimensions of Marketing" Okigwe: Avan Global Publications Pp. 18-26.

Bearden, W.O., Ingram, T.N. \& Laforge, R.W. 2004 "Marketing: Principles, and Perspectives,Boston: McGraw-Hill Pg. 84.

Blythe, J. 2008. “Consumer Behaviour” Uk: Thanson, Pp. 190.

Durmaz, Y. 2014. "The Influence of Cultural Factors on Consumer Buying Behaviour and anApplication in Turkey". Global Journal of Management and Business Research: $\quad$ E $\quad$ Marketing” 14(1) Pp. 36-42.

De-Silva, P.H.G.J., Alapattu, N.S.B.M. \& Sanchika, A.I. 2010. "A Study of the CulturalParameters Associated with Meat Purchasing and Consumption

SocioofSouthern Province, Siri Lanka" The Journal of Agricultural Sciences 5(2).

HemaPatil and BBlakkappa 2012. "The Influence of Culture on Cosmetics Consumer Behaviour”. IOSR Journal of Business and Management (IOSRJBM) 3(4) Pp. 41-47.

Ijewere, A.A. \& Odia, E.O. 2012. "Cultural Influences on Product Choice of the Nigerian Consumer" Indian Journal of Economics \& Business 11(1) Pp. 139-155.

Kotler, P, Bowen, J.T \& Makens, J.C 2010. "Marketing for hospitality and Tourism" $5^{\text {th }} \quad$ Edition, $\quad$ Boston Pearson Pg. 151.

Kotler, P. 2002. Marketing Management, India: Prentice Hall.

Kotler, P. and Keller, K. L. 2009. Marketing Management, New Jersey: Pearson Prentice Hall.

Nkang, M.O. \& Effiong, J.B 2014. “The Influence of Consumer's Perception on Pork andPoultryMeat 
Consumption in Calabar South LGA, Cross River State" International Journal of Agricultural Science Research 4(5) Pp. 086-091.

Rani, P. 2014. "Factors Influencing Consumer Behaviour” Int.J.curr.Res. Aca.Rev. 2(9): 52-61.

Sethi, I. \& Chawla, A.S. 2014. "Influence of Cultural, Social and Marketing Factors on the Buying Behaviour of Telecom Users: A Comparative Study of Rural, Semi-Urban and Urban Areas in and Around Chandigarh. Journal of Marketing Management 2(1) Pp. 98. Solomon, M.R. 2011. "Consumer Behaviour Buying, Having and Being" 9th Edition Boston: Pearson Pp. 33.

Speiers, S., Gundala, R.R. \& Singah, M. 2014. "Culture and Consumer Behaviour- A study of Trinidad \& Tobago and Jamaica" International of Journal of Marketing $\quad$ Studies 6(4) Pp.92-99.

Umoren, U. E. 1996. Anthropology Contextualized in Nigerian Peoples and Culture, Unpublished Monograph, RSUST, Port-Harcourt. 